International Journal of Development, Vol.8, No.(1) (2019): 105-111

ISSN: 2314-5536

e-ISSN: 2314-5544 (Online)

www. ijd.byethost13.com

e-mail: fas_ijd@yahoo.om

\title{
Cobalt doped carbon xerogels as efficient supercapacitor electrodes
}

\author{
Hany K. Afify ${ }^{1}$, Abdalla Abdelwahab ${ }^{2}$, Hesham S. Abdel-Samad ${ }^{1}$ and Hamdy H. \\ Hassan $^{1^{*}}$ \\ 1-Chemistry Department, Faculty of science, Ain-Shams Univ., Abassia, Cairo, 11566, Egypt \\ 2-Materials Science and Nanotechnology Department, Faculty of Postgraduate Studies for \\ Advanced Sciences (PSAS), Beni-SuefUniversity, 62511 Beni-Suef, Egypt. \\ *Corresponding author: hamdihh@sci.asu.edu.eg
}

\begin{abstract}
Carbon xerogel and cobalt doped carbon xerogel are successfully prepared from resorcinol-formaldehyde monomers by the sol-gel process. $\mathrm{N}_{2}$ adsorption/desorption isotherms technique are used to characterize the surface texture and pore size distribution of prepared samples. The measured BET specific surface areas for the carbon xerogel and the cobalt doped carbon xerogel are 796.9 and $701.9 \mathrm{~m}^{2} \cdot \mathrm{g}^{-1}$, respectively. These materials were tested as electrodes in a symmetric supercapacitor two-electrode configuration using $1 \mathrm{M}$ $\mathrm{H}_{2} \mathrm{SO}_{4}$ electrolyte by means of cyclic voltammetery technique. The cobalt doped sample exhibits relatively high specific capacitance of $231 \mathrm{~F}^{-g^{-1}}$ (at $0.1 \mathrm{~A} \cdot \mathrm{g}^{-1}$ ). The presence of cobalt species inside the carbon structure of xerogel lead to lowering the specific surface area, increasing the mesoporosity and consequently enhancing the accessibility for electrolytic ions inside the pores of the cobalt doped samples.
\end{abstract}

Key words: Cobalt-doped carbon xerogel; Supercapacitors; mesoporosity.

\section{INTRODUCTION}

Nowadays the renewable energy conversion devices such as solar cells, fuel cells and wind turbines ${ }^{[1]}$,as well asthe energy storage devices like lithium ion batteries ${ }^{[2]}$ and supercapacitorsacquire a great interest of researchers all over the world. Supercapacitors are environmental friendly electrochemical energy storage devisesthat attracted a lot of attention due totheirhigh power density, long life cycle, high charge discharge rates, and wide ranges of operating temperature ${ }^{[3-5]}$. The supercapacitors can play a vital role in complementing the gap between the high energy storage functions of batteries and fuel cells and the high power density of the traditional dielectric capacitors ${ }^{[6,7]}$.

Super capacitors consist of two electrodes separated by insulator di-electrical material. The specific surface area, pore structure, and chemical stability of electrode materialsare very important parameters for determining the performance of the supercapacitors. Recently, carbon materials such ascarbon nanotubes ${ }^{[8]}$, carbongels $^{[9,10]}$ and graphene ${ }^{[11,12]}$ are intensively used in designing the supercapacitor electrodes. In addition, the carbon materials have high electrical conductivity, chemical inertness, abundance, and low $\operatorname{cost}^{[13,14]}$.

For instance, carbon gels, including aerogel, cryogel and xerogel, are characterized bya controllable large specific surface area through adjusting the micro - meso pores ratio. The micropores are essential for increasing the surface area and providing the place for storing the ions of the dissociated electrolyte. However, themeso pores offer channels for the electrolyte to pass through and reach the entire micropore structurewith sufficient amounts. Consequently, carbon xerogelsare good candidates formany recent energy applications such as fuel cells ${ }^{[15-17]}$, hydrogen storage adsorption ${ }^{[18,}{ }^{19]}$, lithium ion batteries ${ }^{[20-22]}$ and supercapacitors ${ }^{[23-26]}$. Carbon xerogels can be doped with active materials such as $\mathrm{Mn}, \mathrm{Ni}$, $\mathrm{Fe}, \mathrm{Pd}^{[27]}$ or metal oxides ${ }^{[17]}$ in order to enhance its activity. 
Hany K. Afify et al.

Although, cobalt metal is intensively used in energy devices, it was not tested as a dopant for the carbon gels in supercapacitor applications to the best of our knowledge. The aim this work, is focused in preparing carbon xerogel with a high surface area and doping it with cobalt metal as a promising highly efficient supercapacitor electrode. In addition, the performance of the prepared xerogels is compared with some similar published electrodes.

\section{Synthesis of carbon xerogel $(\mathrm{X})$}

\section{EXPERIMENTAL}

Carbon xerogel was synthesized by polycondensation of resorcinol and formaldehydein molar ratio of 1:2 respectively in the presence of aqueous solution of $\mathrm{Na}_{2} \mathrm{CO}_{3}$ as catalyst. All these chemicals were of analytical grade and were purchased from the ADWIC laboratory chemicals (Egypt). The components were mixedand stirred well to get clear solutions. Then the mixture wasdivided into equal portions, poured into glass tubes and sealed from both sides to minimize solvent evaporation.The glass molds were dried at $40^{\circ} \mathrm{C}$ overnight; then, maintained constant at $80{ }^{\circ} \mathrm{C}$ for 5 days. The obtained organic gel was then soaked for 5 days in acetone and dried in microwave oven. Finally, Carbon xerogel (X) was obtained after carbonizing the resultant xerogel at $900{ }^{\circ} \mathrm{C}$ in nitrogen atmosphere in a special tube furnace ${ }^{[28-30]}$.

\section{Synthesis of cobalt doped carbon xerogel $(\mathrm{Co}-\mathrm{X})$}

Preparation of cobalt doped carbon xerogel $(\mathrm{Co}-\mathrm{X})$ was achieved in the same manner as $\mathrm{X}$, but with replacing $\mathrm{Na}_{2} \mathrm{CO}_{3}$ by cobalt acetate $\mathrm{Co}\left(\mathrm{CH}_{3} \mathrm{COO}\right)_{2} \cdot 4 \mathrm{H}_{2} \mathrm{O}$ (Sigma Aldrich, USA) that works as the catalyst and the dopant as well. The molar ratioof resorcinolformaldehyde mix tocobalt acetatewas 100:1.

\section{Characterization of surface texture:}

The surface texture of theprepared samples wascharacterized by $\mathrm{N}_{2}$ adsorption/desorption at $-196^{\circ} \mathrm{C}$ using a BET-Surface area analyzer, Gemini VII 2390 Analyzers, Micromeritics,USA, instrument. The samples were previouslydegassed for two hours under Heliumg as flow at $110^{\circ} \mathrm{C}$.

\section{a. Electrochemical characterization}

Electrochemical measurements of supercapacitor performance were achieved using a Swage lok two-electrode cell setup. The electrodes were prepared by mixing the electroactive $\mathrm{X}$ material and polytetrafluoroethylene (PTFE) (60\% suspension in water) as binder with a mass ratio of 90:10. The mixture was dried in oven at $100{ }^{\circ} \mathrm{C}$ for $24 \mathrm{hrs}$. A portion of $4 \mathrm{mg}$ of the resulted paste was loaded and pressed onto a graphite disc with diameter of $0.8 \mathrm{~cm}$ which employed as a current collector. The samples were soaked in $1 \mathrm{M} \mathrm{H}_{2} \mathrm{SO}_{4}$ for $72 \mathrm{hrs}$ prior to the electrochemical measurements to ensure complete diffusion of electrolyte ions into the pores of the active material. The capacitor cell was built up of two compositediscs electrodes separated by filter paper witted withelectrolyte in the Swagelok system. All electrochemical measurements were performed using Gamry Reference 3000electrochemical workstation. The electrochemical cyclic voltammetry $(\mathrm{CV})$ technique was used to estimate the performance of the prepared electrodes in a potential range from 0 to $0.8 \mathrm{~V}$ with different scan rates of $100,50,20,10,5,3,1$ and $0.5 \mathrm{mV}^{-1}{ }^{-1}$.

\section{Surface characterization and pore size analysis: \\ RESULTS AND DISCUSSION}

The typical $\mathrm{N}_{2}$ adsorption/desorption isotherms at $-196^{\circ} \mathrm{C}$ for $\mathrm{X}$ and Co-X are shown in Figure (1) and the data extracted from the isotherms including BET specific surface area 
$\left(\mathrm{S}_{\mathrm{BET}}\right)$, total pore volume $\left(\mathrm{V}_{\mathrm{P}}\right)$ and the average pore diameter $(\mathrm{d})$ are compiled in Table (1).The adsorption desorption isotherm obtained from $\mathrm{X}$ sample can be considered asa composite of types I andIV with a very narrow $\mathrm{H} 4$ hysteresis behavior based on the IUPAC classification indicating that such carbon matrix has a combined micro-mesoporous structure ${ }^{[31]}$. This is consistent with the high $\mathrm{S}_{\mathrm{BET}}$ of $796.9 \mathrm{~m}^{2} \cdot \mathrm{g}^{-1}$ and its (d) value of $2.88 \mathrm{~nm}$ which is slightly higher than the micropore diameter borderline (Table 1).

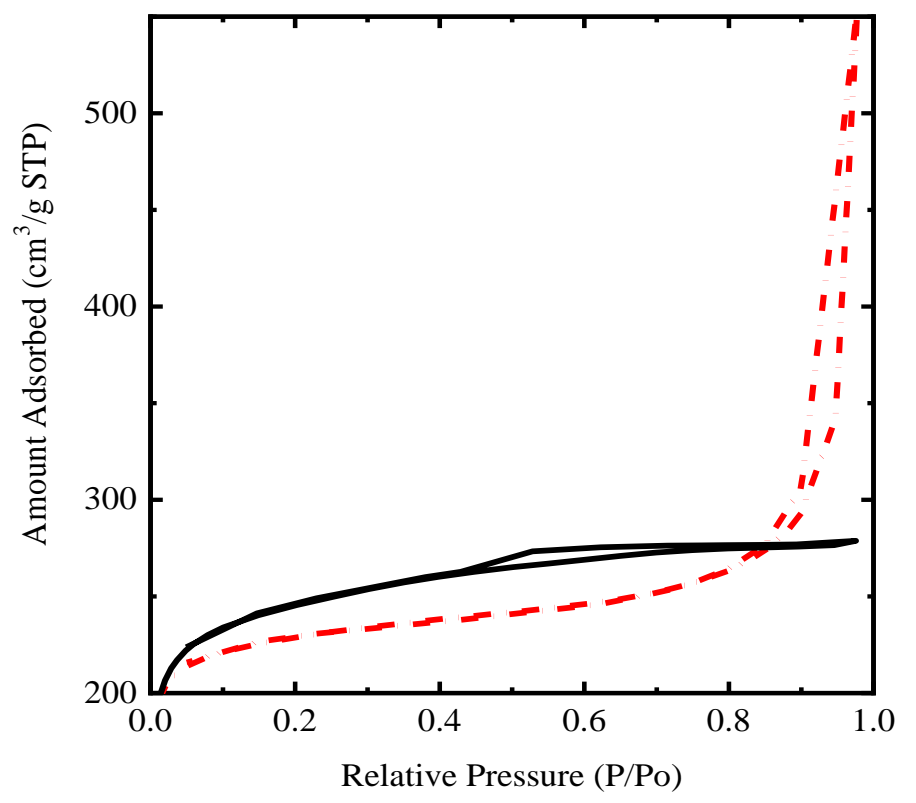

Fig. 1. $\mathbf{N}_{2}$ adsorption/desorption isotherms for Xerogel sample; $X$ (black solid line) and cobalt/Xerogel sample; Co-X (red dashed line).

On the other hand, the adsorption/desorption isotherm of cobalt doped sample (Co-X) is typically type II with type H1 hysteresis. Moreover, introducing the cobalt dopant leads to a slight decrease in $S_{B E T}$ of Co-X to $701.9 \mathrm{~m}^{2} \cdot \mathrm{g}^{-1}$, and enlargement of its (d) to $4.33 \mathrm{~nm}$ (Table 1) indicating the enhancement of the mesoporosity. This is consistent with the increase of the adsorbed volume at high relative pressure $\left(\mathrm{P} / \mathrm{P}^{0}\right)$ due to the mesopores saturation. This development of mesoporous structure of the carbon xerogel matrix may be related to the incorporation of the cobalt species intothe $\mathrm{X}$ micro-mesopore system.It is worth noting that increasing the mesoporosity in xerogel matrix improves its availability for the electrolyte through providingnetworks for fast ion transport ${ }^{[32]}$. Meanwhile, themicropores supply a large surface area together with strong adsorption ability to improve capacitance and act as ion traps for energy storageas well ${ }^{[32,33]}$.

Table 1: Surface area and pore size analysis of the prepared materials

\begin{tabular}{cccc}
\hline Sample & $\begin{array}{c}\text { Specific surface area } \\
\left(\mathbf{S}_{\mathbf{B E T}}\right)\end{array}$ & $\begin{array}{c}\text { Pore volume } \\
\left(\mathbf{V}_{\mathbf{P}}\right)\end{array}$ & $\begin{array}{c}\text { Pore diameter } \\
(\mathbf{d})\end{array}$ \\
& $\mathbf{m}^{\mathbf{2}} \cdot \mathbf{g}^{-\mathbf{1}}$ & $\mathbf{c m}^{\mathbf{3}} \cdot \mathbf{g}^{\mathbf{- 1}}$ & $\mathbf{n m}$ \\
\hline $\mathbf{C X}$ & 796.9 & 0.267 & 2.88 \\
$\mathbf{C o -} \mathbf{C X}$ & 701.9 & 0.163 & 4.33 \\
\hline
\end{tabular}


Hany K. Afify et al.

2.Cyclic voltammetry characterization of the carbon xerogel $(X)$ and cobalt doped carbon xerogel (Co-X)composites:

The cyclic voltammetric behavior of the $\mathrm{X}$ and Co-X samples at different scan ratesare shown in Figs. 2 and 3 respectively. The CV sexhibit a rectangular shaped profile characteristic of an ideal capacitive behavior. This behavior remains stable in the studied range of scan rates. The integrated area of theof the $\mathrm{CV}$ of $\mathrm{X}$ islower than that for Co-X. This indicates a better capacitive performance of Co-X. For instance, the specific capacitancesmeasuredfor $\mathrm{X}$ and Co-X atscan rate (v)of $1 \mathrm{mV} . \mathrm{s}^{-1}$ are 159 and $231 \mathrm{~F} . \mathrm{g}^{-}$ ${ }^{1}$ respectively.Table (2), summarized the calculated specific capacitances of both $\mathrm{X}$ and CO$\mathrm{X}$ samples at different values of scan rates. The results revealed that thecapacitance of both samples increases by decreasing the scan rate due to ion exchange mechanism. At lower scan rates the ions have enough time to intercalate and de-intercalate, which facilitates storing more charge ${ }^{[34]}$.

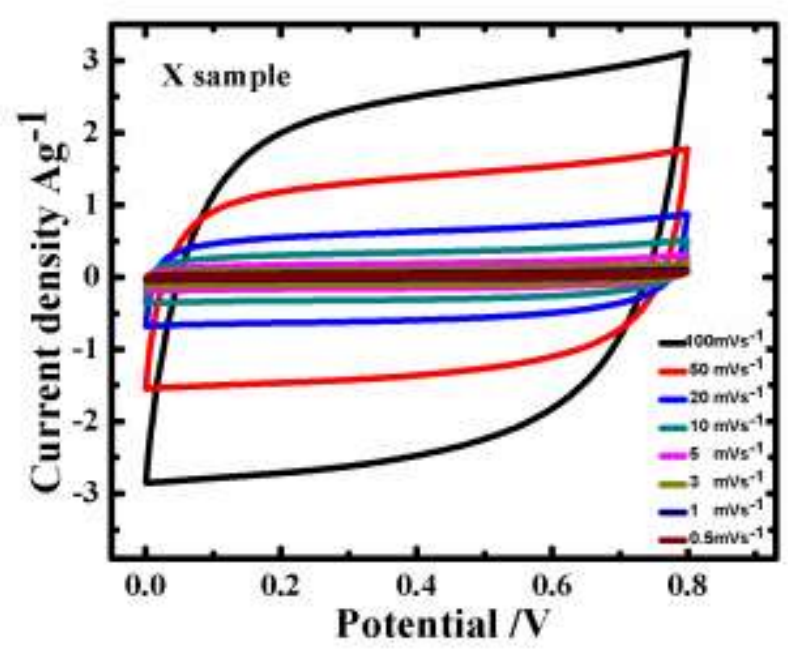

Fig. $2 \mathrm{CV}$ curves in $\mathbf{M M ~ H}_{2} \mathrm{SO}_{4}$ for Xerogel electrode at different scan rate values.

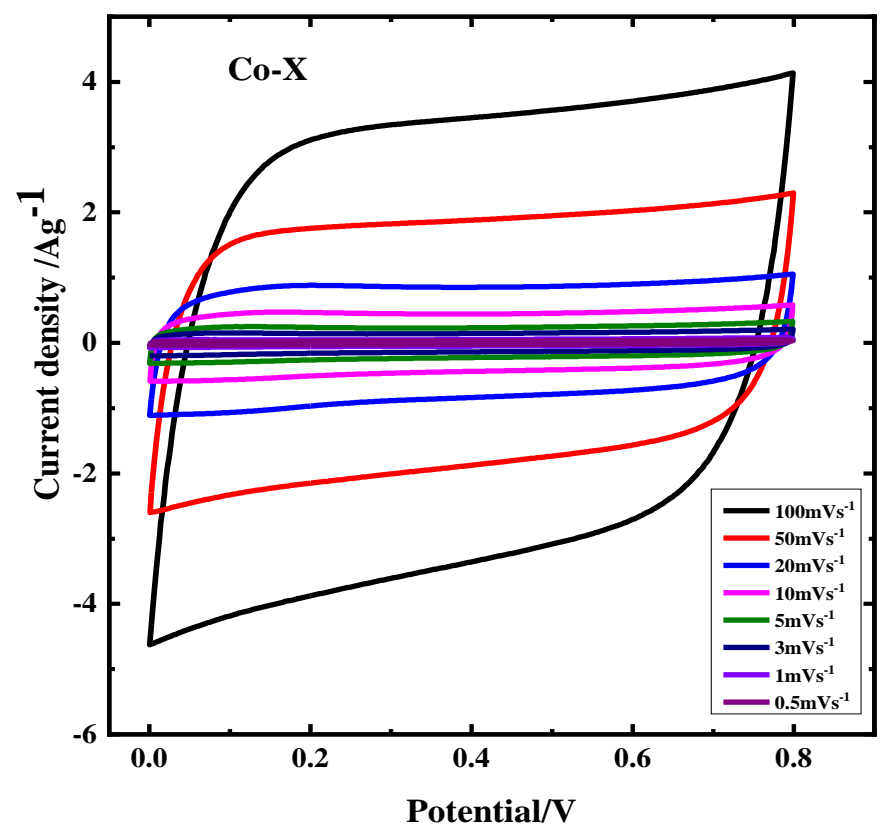

Fig.3. CV curves in $1 \mathrm{M}$ H2SO4 for Co-X electrode at different scan rates values. 


\section{Cobalt doped Carbon Xerogels as Efficient Supercapacitor Electrodes}

Also, the obtained results together with those of Fig.1 and Table 1, lead to the conclusion that cobalt doping in carbon xerogels enhances the electrochemical activity due to faster ionic accessibility inside the pores (owing to improving the mesoporosity) and creation of new cobalt active sites.

Table 2: Effect of scan rate on the specific capacitance of $X$ and Co-X samples.

\begin{tabular}{ccc}
\hline $\begin{array}{c}\text { Scan rate } \\
\mathbf{m V s}^{-1}\end{array}$ & $\begin{array}{c}\text { Specific capacitance } \\
\text { F.g }^{-1}\end{array}$ \\
& $\mathrm{X}$ & Co-X \\
\hline 100 & 90 & 142 \\
50 & 102 & 161 \\
20 & 116 & 185 \\
10 & 125 & 198 \\
5 & 134 & 208 \\
3 & 139 & 215 \\
1 & 159 & 231 \\
0.5 & 188 & 243 \\
\hline
\end{tabular}

Moreover, it is worth noting that the present $\mathrm{X}$ and Co-X electrodes have higher capacitance values than almost all published electrodes as shown in the rough comparison of Table 3. Accordingly, our Co-X represents a hopeful highly efficient material as a supercapacitor electrode.

Table 3: Comparison between the present $\mathrm{X}$ and $\mathrm{Co}-\mathrm{X}$ electrodes and other electrodes.

\begin{tabular}{ccccc} 
Electrode Material & Electrolyte & $\begin{array}{c}\text { Capacitance Scan rate } \\
\mathbf{F . g}\end{array}$ & $\mathbf{v} / \mathbf{m V ~ \mathbf { s } ^ { - 1 }}$ & Reference \\
\hline $\mathbf{1 0} \mathbf{w t} \% \mathbf{~ N i}-\mathbf{X}$ & $6 \mathrm{M} \mathrm{KOH}$ & 103 & 1 & {$[35]$} \\
$\mathbf{X}$ & $30 \% \mathrm{wt} \mathrm{KOH}$ & 210 & 1 & {$[36]$} \\
$\mathbf{X}$ & $1 \mathrm{MH}_{2} \mathrm{SO}_{4}$ & 159 & 1 & present work \\
$\mathbf{C o}-\mathbf{X}$ & $1 \mathrm{MH}_{2} \mathrm{SO}_{4}$ & 231 & 1 & present work \\
\hline
\end{tabular}

\section{Conclusions:}

Two carbon network samples namely, carbon xerogel $(\mathrm{X})$ and cobalt doped carbon xerogel (Co-X) were prepared by the sol-gel prior to hydrothermal processes and well characterized by some surface and electrochemical techniques. The analysis of $\mathrm{N}_{2}$ adsorption/ desorption isotherms revealed that the specific surface area of Co-X is slightly lower than that of undoped sample. However, the porous structure of Co-X is enlarged to the mesoporous scale due to the invasion of cobalt species through the porous carbon network. Moreover, cobalt doping in carbons xerogels enhances the electrochemical activity and increases its capacitance due to faster ionic accessibility inside the pores (improving the mesoporosity) and creation of new cobalt active sites.

\section{REFERENCES}

1. Weinzierl, C. and U. Krewer (2016). Model-based analysis of water management at anode of alkaline direct methanol fuel cells. Chem. Engineering Sci., 143: 181-193. 


\section{Hany K. Afify et al.}

2. Kakunuri, M.; S. Kali and C.S. Sharma (2016). Catalytic graphitization of resorcinolformaldehyde xerogel and its effect on lithium ion intercalation. J. Analytical and Appl. Pyrolysis, 117: 317-324.

3. Nishino, A.; A. Yoshida and I. Tanahashi (1985). Electric double layer capacitor. Google Patents.

4. Conway, B.E. (1999). Electrochemical supercapacitors Scientific Fundamentals and Technological Applications. New York: Kluwer Academic/ Plenum Publishers. 366.

5. Frackowiak, E. and F. Beguin (2001). Carbon materials for the electrochemical storage of energy in capacitors. Carbon, 39(6): 937-950.

6. Largeot, C., et al. ((2008). Relation between the ion size and pore size for an electric double-layer capacitor. J. Am. Chem. Soc., 130(9): 2730-2731.

7. Zhi, M., et al. (2013). Nanostructured carbon-metal oxide composite electrodes for supercapacitors: a review. Nanoscale, 5(1): 72-88.

8. Park, J., et al. (2014). Energy-density enhancement of carbon-nanotube-based supercapacitors with redox couple in organic electrolyte. ACS Applied Materials \& Interfaces, 6(22): 19499-19503.

9. Fang, B. and L. Binder (2006). A modified activated carbon aerogel for high-energy storage in electric double layer capacitors. J. Power Sources, 163(1): 616-622.

10. Wang, Y.-H., et al. (2014). Dispersing WO 3 in carbon aerogel makes an outstanding supercapacitor electrode material. Carbon, 69: 287-293.

11. Kim, T., et al. (2013). Activated graphene-based carbons as supercapacitor electrodes with macro-and mesopores. Acs Nano, 7(8): p. 6899-6905.

12. Wang, C.C.; H.C. Chen and S.Y. Lu (2014). Manganese oxide/graphene aerogel composites as an outstanding supercapacitor electrode material. Chemistry-A European J., 20(2): p. 517-523.

13. Pandolfo, A. and A. Hollenkamp (2006). Carbon properties and their role in supercapacitors. J. Power Sources, 157(1): 11-27.

14. Zhang, L.L. and X. Zhao (2009). Carbon-based materials as supercapacitor electrodes. Chemical Society Reviews, 38(9):. 2520-2531.

15. Job, N., et al. (2008). Carbon xerogels as catalyst supports for PEM fuel cell cathode. Energy Conversion and Management, 49(9): 2461-2470.

16. Liu, B. and S. Creager (2010). Carbon xerogels as Pt catalyst supports for polymer electrolyte membrane fuel-cell applications. J. Power Sources, 195(7):1812-1820.

17. EL-Deeb, M.M., et al. (2018). Effect of pore geometry on the electrocatalytic performance of nickel cobaltite/carbon xerogel nanocomposite for methanol oxidation. Electrochimica Acta, 259: 77-85.

18. Kang, K.Y.; B.I. Lee and J.S. Lee (2009). Hydrogen adsorption on nitrogen-doped carbon xerogels. Carbon, 47(4): 1171-1180.

19. Tian, H.-Y., et al. (2010). A synthesis method for cobalt doped carbon aerogels with high surface area and their hydrogen storage properties. international journal of hydrogen energy, 35(24): 13242-13246.

20. Lv, P., et al. (2014). Facile preparation and electrochemical properties of carbon coated Fe $3 \mathrm{O} 4$ as anode material for lithium-ion batteries. J. Power Sources, 259: 92-97.

21. Hasegawa, T., et al. (2004). Preparation of carbon gel microspheres containing silicon powder for lithium ion battery anodes. Carbon, 42(12): 2573-2579.

22. Alcántara, R., et al. (2005). Carbon microspheres obtained from resorcinol-formaldehyde as high-capacity electrodes for sodium-ion batteries. Electrochemical and Solid-State Letters, 8(4): A222-A225. 


\section{Cobalt doped Carbon Xerogels as Efficient Supercapacitor Electrodes}

23. Mezzavilla, S., et al. (2012). Carbon xerogels as electrodes for supercapacitors. The influence of the catalyst concentration on the microstructure and on the electrochemical properties. J. Mater. Sci.,47(20): 7175-7180.

24. Ordeñana-Martínez, A. and M. Rincón (2016). Composite MWCNT/carbon xerogelnafion electrode for energy storage. J. Solid State Electrochem., 20(5): 1391-1396.

25. Chang, Y.-M., C.-Y. Wu and P.-W. Wu (2013). Synthesis of large surface area carbon xerogels for electrochemical double layer capacitors. J.Power Sources, 223: 147-154.

26. Calvo, E., et al. (2013). Optimizing the electrochemical performance of aqueous symmetric supercapacitors based on an activated carbon xerogel. J Power Sources, 241:776-782.

27. Job, N., et al. (2004). Synthesis of transition metal-doped carbon xerogels by solubilization of metal salts in resorcinol-formaldehyde aqueous solution. Carbon, 42(15): 3217-3227.

28. Moreno, A., et al. (2013). Carbonisation of resorcinol-formaldehyde organic xerogels: effect of temperature, particle size and heating rate on the porosity of carbon xerogels. J. Analyt. and Appl. Pyrolysis, 100: 111-116.

29. Rojas-Cervantes, M.L.( 2015). Some strategies to lower the production cost of carbon gels. J. Mater. Sci.,50(3): 1017-1040.

30. Job, N., et al. (2005). Carbon aerogels, cryogels and xerogels: influence of the drying method on the textural properties of porous carbon materials. Carbon, 43(12): 2481-2494.

31. Thommes, M., et al.(2015). Physisorption of gases, with special reference to the evaluation of surface area and pore size distribution (IUPAC Technical Report). Pure and Appl. Chem., 87(9-10): 1051-1069.

32. Guo, Y., et al. (2014). Hierarchical porous carbon derived from sulfonated pitch for electrical double layer capacitors. J. Power Sources, 252: 235-243.

33. Chen, H., et al. (2012). Porous carbon with tailored pore size for electric double layer capacitors application. Appl.Surface Sci., 258(16): 6097-6102.

34. Nagamuthu, S.; S. Vijayakumar and G. Muralidharan (2014). Ag incorporated Mn 3 O 4/AC nanocomposite based supercapacitor devices with high energy density and power density. Dalton Transactions, 43(46): 17528-17538.

35. Skowroński, J.M. and M. Osińska (2012).Effect of nickel catalyst on physicochemical properties of carbon xerogels as electrode materials for supercapacitor. Current Appl. Physics, 12(3): 911-918.

36. Zhang, L., et al. (2007).Structure and electrochemical properties of resorcinolformaldehyde polymer-based carbon for electric double-layer capacitors. Carbon, 45(7): 1439-1445.

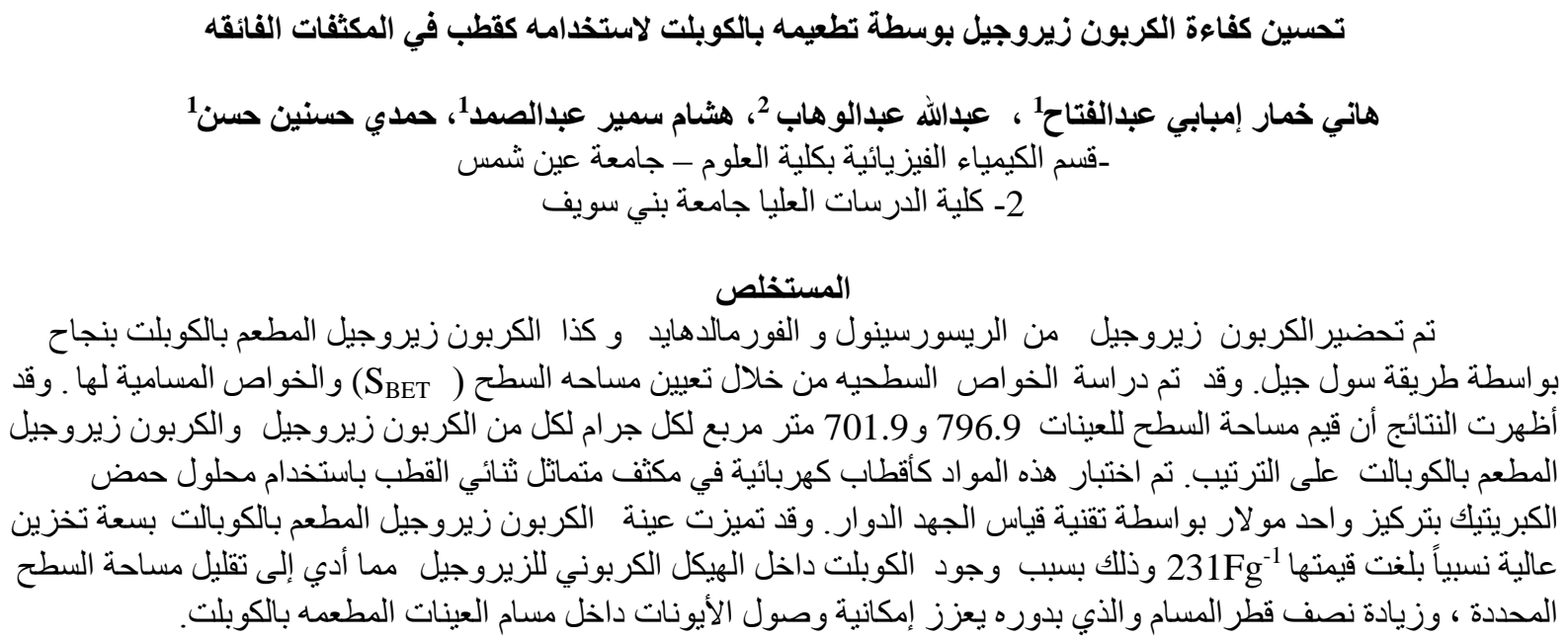

